\title{
Synchronous primary intrapulmonary and mediastinal thymoma-A case report
}

\author{
Zuoqing Song, Xiaohong Xu, Shujun Li, Sen Wei, Jun Chen", Qinghua Zhou*
}

\begin{abstract}
We report an extremely rare case of Synchronous primary intrapulmonary and mediastinal thymoma in a Chinese patient. We describe the histological and radiological findings, which support the possibility of multicentric thymoma. Resection of the mass in the left anterior superior mediastinum and upper lobectomy of right lung were performed, with lymph Nodes clearance, superior vena cava, left and right brachiocephalic veins resection, reconstruction of left brachiocephalic vein to right auricle and reconstruction of right brachiocephalic vein to superior vena cava.
\end{abstract}

\section{Introduction}

Thymomas are tumors derived from thymic epithelial cells and have an incidence of 0.15 per 100000[1]. Primary intrapulmonary thymomas are defined as thymomas arising in an intrapulmonary location without an associated mediastinal component and are very rare[2]. Here we present a successfully resected case of synchronous primary intrapulmonary and mediastinal thymoma with vascular reconstruction.

\section{Case report}

A 55-year-old Chinese man was admitted with a history of progressive exertional dyspnea of 55 days' duration and a radiological finding of an anterior mediastinal mass for 7 days. The patient had no clinical features of myasthenia gravis. An enhanced Chest computed tomographic scan revealed a $5.5 \mathrm{~cm} \times 6.0 \mathrm{~cm} \times 4.1 \mathrm{~cm}$ mass in the anterior segment of the right upper lobe with continuation to some mediastinal swelling lymph nodes. Multiple swelling lymph nodes could be found in the mediastinum (Figure 1A, B, Figure 2A, B, C). Three-D reconstruction showed the superior vena cava, whose lumen was unobstructed but deformated under the compression of the mass (Figure 1C). A computed tomographic scanning of the brain and bones were normal. An exploratory limited right thoracotomy was undertaken through a median sternotomy. A soft

\footnotetext{
*Correspondence: huntercj2004@yahoo.com; zhouqh1016@yahoo.com.cn Department of Lung Cancer Surgery, Tianjin Key Laboratory of Lung Cancer Metastasis and Tumor Microenvironment, Tianjin Lung Cancer Institute, Tianjin Medical University General Hospital, Tianjin 300052, China
}

encapsulated mass $(3.5 \mathrm{~cm} \times 4.0 \mathrm{~cm} \times 5 \mathrm{~cm})$ was found in the left anterior superior mediastinum, with invasion to the left pericardium and visceral pleura, adhesive to partial superior lobe of right lung and brachiocephalic vein(Figure 1G, I). In the anterior segment of the right upper lobe, a mass was $6 \mathrm{~cm}$ in diameter, invading the junction of right and left brachiocephalic veins and upper segment of superior vena cava (Figure $1 \mathrm{~F}, \mathrm{H}$ ). Both masses are solitary. Therefore resection of the mass in the left anterior superior mediastinum and upper lobectomy of right lung were performed, with lymph Nodes clearance, superior vena cava, left and right brachiocephalic veins resection, reconstruction of left brachiocephalic vein to right auricle and reconstruction of right brachiocephalic vein to superior vena cava. Microscopically according to the WHO classification, the mediastinal tumor(MT) was a B3/B2 primary thymoma and the mass in the upper lobe of right lung is mainly a B3/B2 primary intrapulmonary thymoma(PIT) with local A type tumors. Histologic evaluation indicated that, CK5 \& CK6 +, EMA + locally, CD5 -, CD99 + (Figure 2. No lymph metastasis was found. Warfarin was applied to the patient as anticoagulation and 50 Gy mediastinal irradiation was given as adjuvant therapy. The patient has since recovered uneventfully and is now being followed up as an outpatient (Figure 1D, E). After follow-up of eight months, there was no significant metastasis or recurrence found by radiological examinations. 

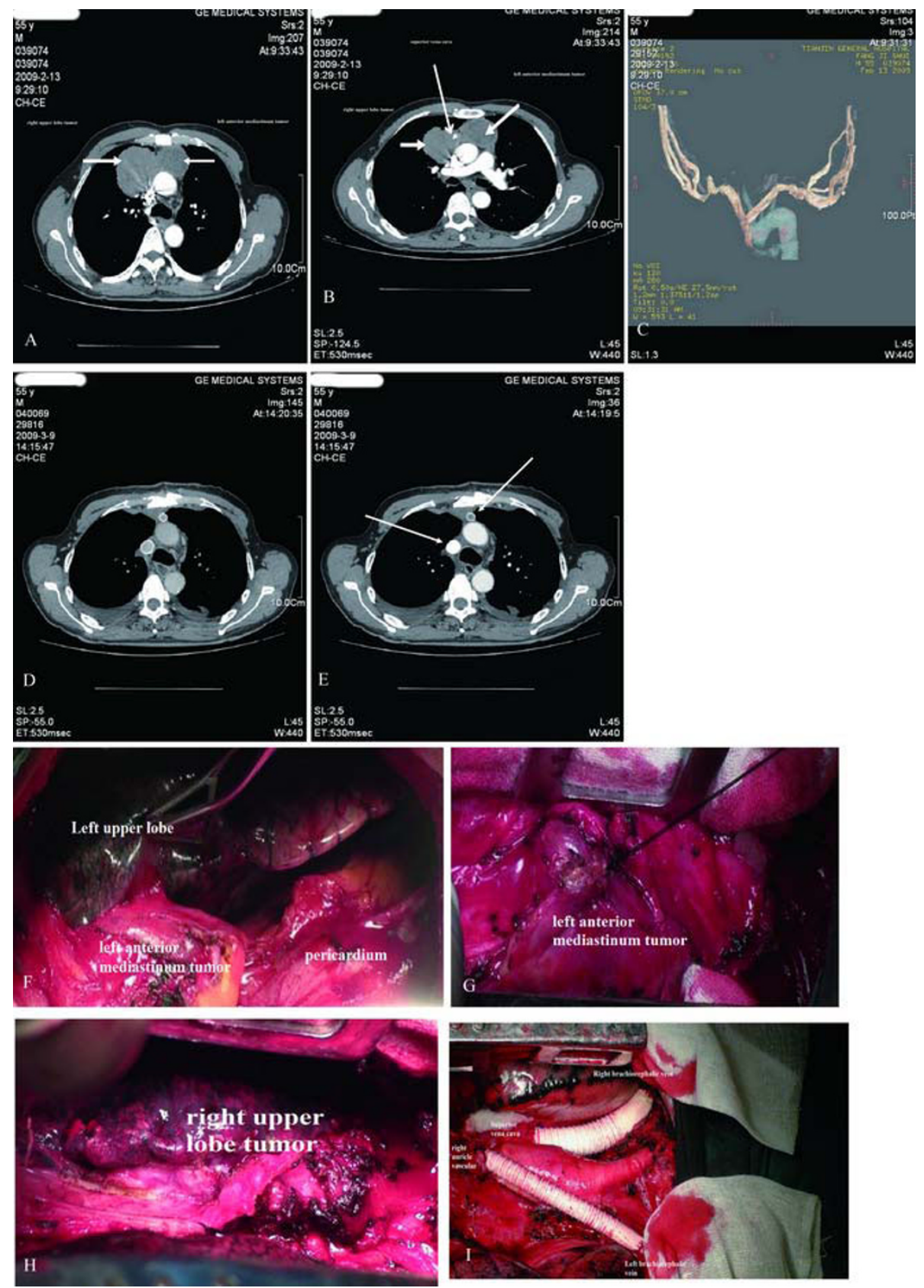

Figure 1 Chest computed tomographic scan. Figure 1A, 1B An enhanced Chest computed tomographic scan revealed a mass in the anterior segment of the right upper lobe with continuation to some mediastinal swelling lymph nodes. Multiple swelling lymph nodes could be found in the mediastinum. Figure C Three-D reconstruction showed the superior vena cava, whose lumen was unobstructed but deformated under the compression of the mass. Figure 1D, 1E Postoperative enhanced Chest computed tomographic scan images. Figure 1F, 1G Surgical findings of the mediastinal mass. Figure $1 \mathrm{H}$ Surgical findings of the intrapulmonary mass. Figure $1 /$ Reconstruction of left brachiocephalic vein to right auricle and reconstruction of right brachiocephalic vein to superior vena cava.

\section{Discussion}

Primary intrapulmonary thymuses are very uncommon, with 28 cases reported to date[2]. Even rarer cases were reported for Synchronous primary intrapulmonary and mediastinal thymoma. The incidence for lung cancer in China increased by $1.63 \%$ from 1988 to 2005 . Some special thoracic malignancies should be paid attention to in China[3]. Primary intrapulmonary thymomas appear to fall into two groups: one is in the hilus of the lung, in relation to the wall of a major bronchus or attached to the pericardium, and the other is peripheral in the lung and beneath the visceral pleura[4]. In the 

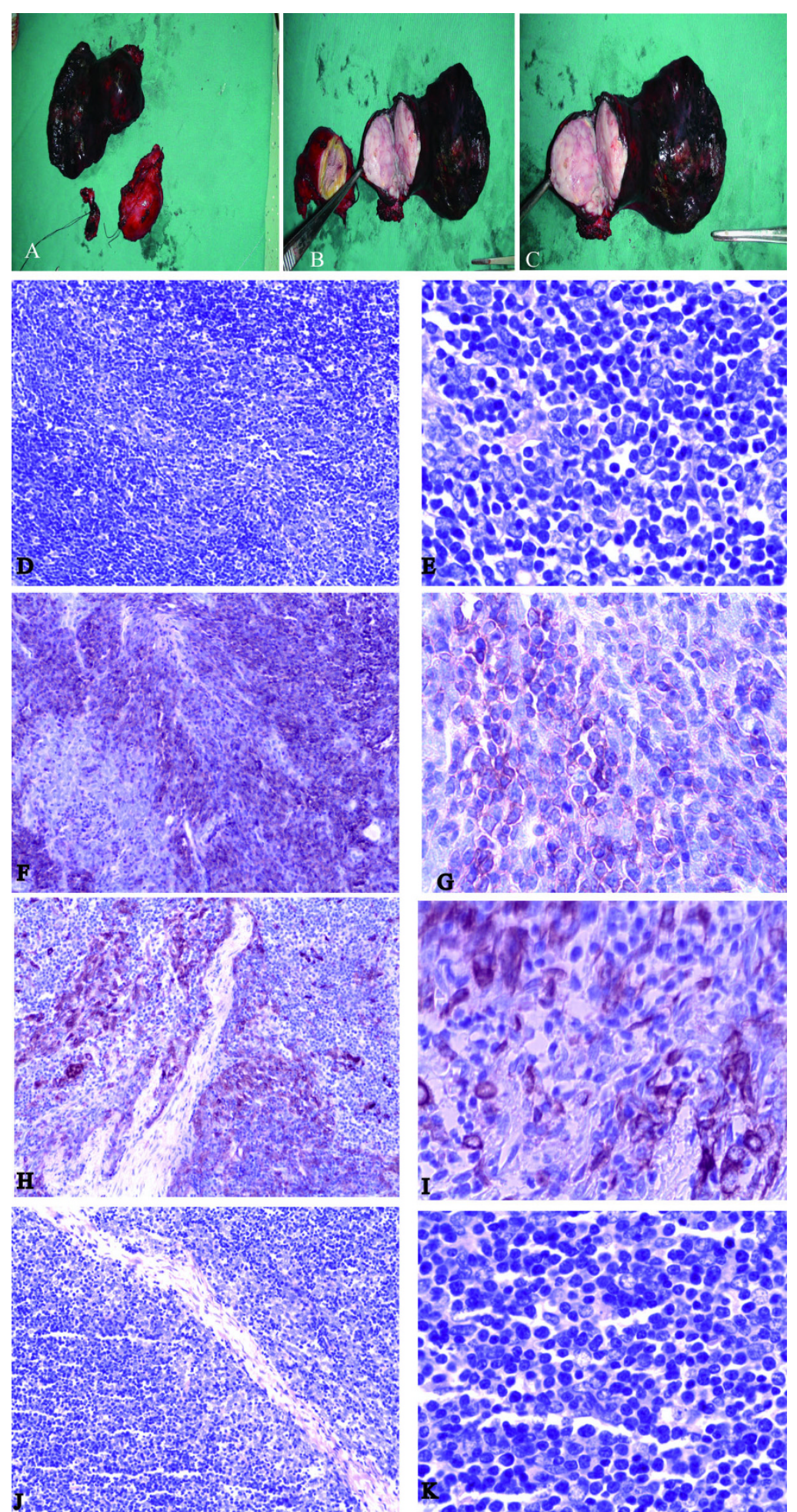

Figure 2 Macro and microscopic observations. Figure $2 \mathrm{~A}, 2 \mathrm{~B}, 2 \mathrm{C}$ The resected intrapulmonary and mediastinal tumors $(3.5 \mathrm{~cm} \times 4.0 \mathrm{~cm} \times 5 \mathrm{~cm}$ and $6 \mathrm{~cm} \times 6 \mathrm{~cm} \times 6 \mathrm{~cm}$, respectively). Figure 2D Histological findings of the primary intrapulmonary tumor(PIT), H\&E $\times 100$. Figure $2 \mathrm{E}$ PIT H\&E $\times 400$. Figure 2F PIT CD99 Immunohistochemistry $\times 100$. Figure 2G PIT CD99 Immunohistochemistry $\times 400$. Figure 2H PIT CK $5 \&$ CK6 Immunohistochemistry $\times 100$. Figure 21 PIT CK $5 \&$ CK6 Immunohistochemistry $\times 400$. Figure $2 J$ Histological findings of the primary mediastinal tumor(MT), H\&E $\times 100$. Figure $2 \mathrm{~K} \mathrm{MT}, \mathrm{H} \& \mathrm{E} \times 400$. 
case of hilar type, the notion that intrapulmonary thymomas are derived from mediastinal thymomas that migrate into the lung with pinching off of the pleural behind them would be acceptable, but it fails to provide a satisfactory explanation for the occurrence of the peripheral[2]. Marchevsky[5] believed intrapulmonary thymomas arose from stem cells, uncommitted germinative cells capable of differentiating along a variety of lines. This theory is supported by the large number of reports of heterotopic, histologically mature tissues within the lung parenchyma, such as thyroid follicules, pancreas, adrenal, liver, neuro-glial tissue and endometrium, or tumors derived from ectopic tissue, such as melanoma, meningioma, glomus or glomangioma, choriocarcinoma, teratoma, ependymoma and, of course, thymoma, which could develop from such stem cells. Multiple thymomas remain controversial as to whether multiple thymomas involve intrathymic dissemination or represent multiple primaries, which could be explained by Marchevsky's theory. Although Bernatz et al. [6] reported 3 out of 138 (2.2\%) thymomas to be multiple primaries, it was difficult to clarify whether the multiple thymomas in their cases involved double primary or dissemination, because they did not mention any close histological characteristics among the multiple thymomas. Since both our cases were totally encapsulated tumors and did not have any dissemination in the other portion, they were considered to be multiple primaries[7]. Therefore our case provided better evidence to support Marchevsky's theory for the development of intrapulmonary thymomas.

The clinical course is that of a slow-growing lesion that remains asymptomatic until it reaches a size causing problems due to local growth, such as pain, bronchial obstruction or hemoptysis. As with mediastinal thymomas, they can be associated with paraneoplastic syndromes, such as myasthenia gravis or Good's syndrome. Resection appears sufficient in non-malignant tumors. In incompletely resected patients, adjuvant radiotherapy should be considered. Long-term regular clinical follow-up is warranted, because of the risk of late local recurrence.

\section{Consent}

Written informed consent was obtained from the patient for publication of this case report and any accompanying images. A copy of the written consent is available for review by the Editor-in-Chief of this journal.

\section{Acknowledgements}

This study was partly supported by the grants from Key Project of National Natural Science Foundation of China(No.30430300), National 973 Program (No.2010CB529405), National 863 Program (No.2006AA02401) and S\&T Support Key Program of Tianjin (09ZCZDSF04100, 09ZCZDSF04000).

\section{Authors' contributions}

ZS, JC and QZ were the primary caregiver for this patient and reviewed the manuscript. SL and SW also cared for this patient. XX performed data collection and drafted the manuscript. All authors read and approved the final manuscript.

\section{Competing interests}

The authors declare that they have no competing interests.

Received: 12 July 2010 Accepted: 28 August 2010

Published: 28 August 2010

\section{References}

1. Engels EA, Pfeiffer RM: Malignant thymoma in the United States: demographic patterns in incidence and associations with subsequent malignancies. Int J Cancer 2003, 105:546-551.

2. Ishibashi H, Takahashi S, Tomoko H, Shibuya J, Suzuki S, Handa M: Primary intrapulmonary thymoma successfully resected with vascular reconstruction. Ann Thorac Surg 2003, 76:1735-1737.

3. Chen WQ, Zhang SW, Zou XN: Evaluation on the incidence, mortality and tendency of lung cancer in China. Thoracic Cancer 2010, 1:35-40.

4. Kalish PE: Primary intrapulmonary thymoma. N Y State J Med 1963, 63:1705-1708.

5. Marchevsky AM: Lung tumors derived from ectopic tissues. Semin Diagn Pathol 1995, 12:172-184.

6. Bernatz PE, Harrison EG, Clagett OT: Thymoma: a clinicopathologic study. J Thorac Cardiovasc Surg 1961, 42:424-444.

7. Okada M, Tsubota N, Yoshimura M, Miyamoto $Y$, Sakamoto T: Two cases of synchronous multiple thymoma. Surg Today 1998, 28:1323-1325.

doi:10.1186/1749-8090-5-69

Cite this article as: Song et al:: Synchronous primary intrapulmonary and mediastinal thymoma-A case report. Journal of Cardiothoracic Surgery 2010 5:69.

\section{Submit your next manuscript to BioMed Central} and take full advantage of:

- Convenient online submission

- Thorough peer review

- No space constraints or color figure charges

- Immediate publication on acceptance

- Inclusion in PubMed, CAS, Scopus and Google Scholar

- Research which is freely available for redistribution

Submit your manuscript at www.biomedcentral.com/submit
C Biomed Central 